\title{
VARIATION OF WATER POTENTIAL AND TRUNK DIAMETER ANSWER AS SENSITIVITY TO THE WATER AVAILABILITY IN TABLE GRAPES
}

\author{
Claudio Silva-Contreras ${ }^{1}$, Gabriel Sellés-Von Schouwen², Raúl Ferreyra-Espada ${ }^{2}$, \\ and Herman Silva-Robledo ${ }^{{ }^{*}}$
}

\begin{abstract}
Variation in trunk diameter (TDV) has been proposed as an indicator of the water status of grape vines, with apparently contradictory results. In Vitis vinifera L. var. Crimson Seedless we evaluated the water potential $(\Psi)$, an indicator normally used to determine the water status of grapes, and TDV, comparing two irrigation treatments which restored $100 \%$ or $50 \%$ of the ETc, to compare the sensitivity of these two indicators to a decrease in soil water. Two evaluation periods of $23 \mathrm{~d}$ each were used, the first during the exponential growth phase and the second in the post-veraison period, when the trunk stops growing. In both periods TDV showed coefficients of variation greater than $25 \%$, compared to the 7-10\% recorded for water potential. However, during the first measuring period (82-105 $\mathrm{d}$ after bud break) the TDV of the treatment with water deficit decreased by more than $30 \%$, while water potential only decreased from $6-12 \%$. In the second measurement period (112-155 d after bud break) in which fruit growth is predominant, the control showed TDV values $100 \%$ greater than those of the treatment with water deficit, while the differences in water potential were between $10 \%$ and $13 \%$. These results demonstrate the sensitivity of the continuous variation of the trunk diameter and the utility of TDV as a criterion for irrigation control, taking into consideration the development stage of the vines.
\end{abstract}

Key words: Water potential, variable displacement sensor, sensitivity, Vitis vinifera.

$I^{n}$ $n$ the study of the soil-water-plant-atmosphere continuum, the response of plants to environmental variables is becoming more and more important. The responses represent particular physiological states; some of them may be used as sensitive indicators of plant water state and some are currently being used as irrigation criteria for diverse crops (Jones, 2004; Cifre et al., 2005). The sensitivity of the variation in water potential $(\Psi)$ and the growth rate of the trunk as indicators of the water state of plants has been evaluated in almonds (Nortes et al., 2005), peaches (Goldhamer et al., 1999) and olives (Moriana and Fereres, 2002).

The measurement of the water potential has been one of the most common ways to determine the water state of plants (Scholander et al., 1965; Steudle, 2004), expressed as leaf water potential ( $\left.\Psi_{\text {(leaf) }}\right)$ or as stem (or xylem) water potential $\left(\Psi_{\text {(stem) }}\right)$ (Choné et al., 2001). Water potential measured at midday has been used as an indicator to quantify the water state of plants (Araujo et al., 1995). Naor $(1998 ; 2000)$ and Choné et al. (2001) showed that the midday $\Psi_{\text {(stem) }}$ is much more sensitive to water stress during a period without water than is the midday $\Psi_{\text {(leaf) }}$.

${ }^{1}$ Universidad de Chile, Facultad de Ciencias Agronómicas, Santa Rosa 11315, Santiago, Chile. "Corresponding author (hsilva@uchile.cl).

${ }^{2}$ Instituto de Investigaciones Agropecuarias INIA, CRI La Platina, Santa Rosa 11610, Santiago, Chile.

Received: 11 August 2011.

Accepted: 10 August 2012.
Growing table grapes require a bigger amount of water than growing grapes for wine, since its management requires a greater leaf cover, greater fruit production, and a larger size of the grapes (Kadir et al., 2007); this results in greater crop coefficients and thus, a greater bigger evapotranspiration (ET, Williams et al., 2003; Williams and Ayars, 2005). In the production of wine grapes a water deficit may be important way to obtain high-quality grapes for the production of exportable wine (Reynolds and Naylor, 1994). By contrast, the production of table grapes for fresh market requires maintaining the highest possible water state in the critical period of growth and fruit development, from setting to veraison, since this is a determining factor of yield and fruit quality.

The daily and seasonal trunk diameter variation (TDV) has been studied as an indicator for irrigation scheduling in a number of fruit species and has been considered as a promising tool because continuous and automated measurements decrease the field work necessary in irrigation operations (Goldhamer and Fereres, 2001; Jones, 2004). Growth is a component of TDV (Génard et al., 2001); thus in order to use this tool it is necessary to know plant phenology and vegetative and reproductive growth periods. The annual cycle of TDV for grapevines has a growth curve clearly divided into four developmental stages (Ton et al., 2004), which are directly related to the development of the fruit. In the first stage, from bud break until a few days before flowering, there are minimum TDV, due to the precipitations and to 
decreases in soil humidity (Silva-Contreras et al., 2008). In the second stage, from flowering to the end of phase 1 of fruit development, the growth in trunk diameter is exponential; this is the most sensitive period for yield and fruit quality (Matthews and Shackel, 2005). The third stage is of short duration and occurs during phase 2 of fruit development; in this stage the trunk stops growing and may decrease slightly in diameter (Ton et al., 2004). In the fourth and final stage, from fruit maturation (phase III) until the leaves fall, the trunk does not grow in diameter (Silva-Contreras et al., 2008), due to the greater carbohydrate demand by the berries (Intrigliolo y Castel, 2007); the variations between days reflect the humidity of the atmosphere and the soil (Ton et al., 2004). Figure 1a (adapted from Silva-Contreras et al. 2008) illustrates stages 2,3 , and 4 of this cycle in relation to the growth of the fruit.

The characteristics of TDV at daily and seasonal scales (Simonneau et al., 1993; Genard et al., 2001; Goldhamer and Fereres, 2001; Steppe et al., 2006) have given rise to five measurement parameters which may be related to the water state of the plants: maximum daily trunk diameter (MXDTD); minimum daily trunk diameter (MNDTD); maximum daily trunk variation (MXDTV), which is the difference between MXDTD and MNDTD; maximum daily trunk growth (MXDTG), the difference
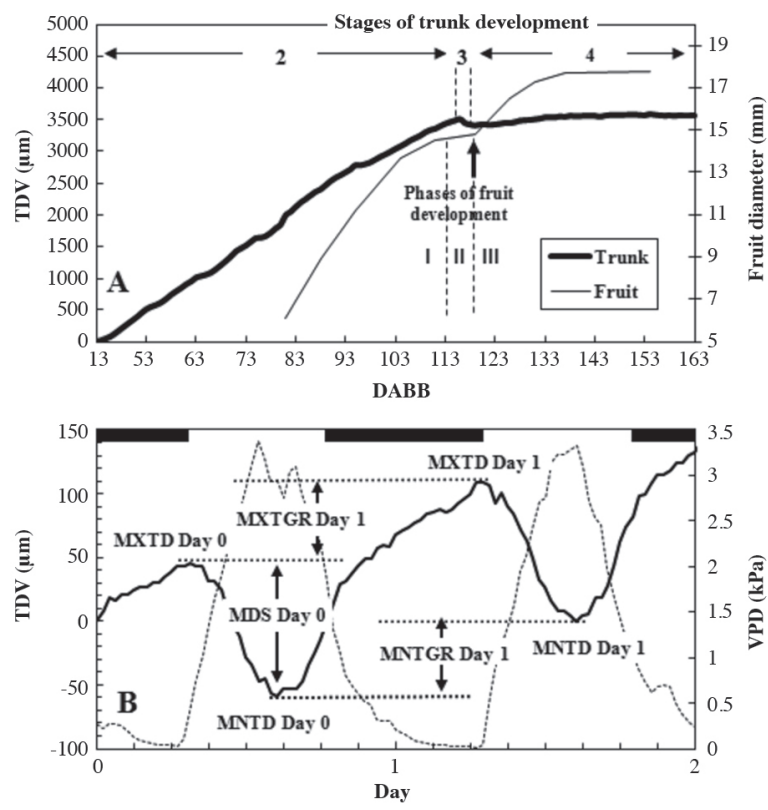

MXTD: maximum daily trunk diameter; MNTD: minimum daily trunk diameter; MDS maximum daily trunk shrinkage; MNTGR: minimum daily trunk growth rate, MXTGR: maximum daily trunk growth rate; VPD: vapor pressure deficit. Horizontal black bars above indicate nighttime hours.

Figure 1. A. Trunk diameter variation (TDV) from 43 to $163 \mathrm{~d}$ after bud break (DABB), and evolution of the equatorial diameter of the fruit in 'Crimson Seedless' grapes (adapted from Silva-Contreras et al., 2008), indicating the stages of annual trunk development (Arabic numbers) and phases of fruit development (Roman numbers). The vertical arrow indicates the beginning of veraison. B. TDV over $2 \mathrm{~d}$. between MXDTD on successive days; and the minimum daily trunk growth, the difference between MNDTD on successive days (Figure 1b).

In the grapes production, irrigation scheduling should have sensitive indicators of the water state during adverse water conditions, in order to avoid any water deficit that affects yield and quality of the fruit. TDV is a promising tool of continuous measurement, which when automated allows more efficient field work and more efficient use of water (Cifre et al., 2005). In Israel, the irrigation of wine grapes has been successively controlled using TDV (Ton et al., 2004; Kopyt and Ton, 2005), considering the changes in trunk diameter on successive days and the daily shrinkage in relation to environmental conditions. However, Intrigliolo and Castel (2007) questioned the diagnosis of water stress using indicators derived from TDV due to its high variability and low correlation with water potential. This disparity in the results obtained with wine grapes may extrapolate to table grapes. Sellés et al. (2004), comparing the growth rate of the trunk in plants with and without water deficit, obtained results favorable to the use of TDV to determine irrigation, between berry set and veraison. Myburg (1996) used a threshold value of daily trunk contraction to define the opportunity of irrigation, with satisfactory results.

If measurements based on soil water content are to be replaced by measurements of plant water content , it is important to determine what type of measurements are the most appropriate to indicate plant water state. However, there is a lack of studies about water relations and the interactions of the indicators of water deficit in the vegetative and reproductive growth of cultivated species. The objective of this study was to analyze the sensitivity of the variation in trunk diameter and leaf and stem water potentials as indicators of the water state for the scheduling of irrigation in table grapes.

\section{MATERIALS AND METHODS}

\section{Study area}

The experiment was performed during the 2004-2005 season in a commercial table grape plantation of Crimson Seedless variety; vines were 7 -yr old and planted at $3.5 \times$ $3.5 \mathrm{~m}$ in an overhead trellised system. The plantation is located in Curimón, San Felipe Province (3044' S; 70³9' W). According to Valenzuela and Lobato (2000), the area's climate is subtropical Mediterranean type semi-arid. Maximum temperatures of the warmest month exceed 32 ${ }^{\circ} \mathrm{C}$, with accumulation thermal spring-summer from 1400 to 1500 days - grade (base $10^{\circ} \mathrm{C}$ ). The average rainfall reaches $350 \mathrm{~mm}$ per year mainly in the winter months (June to August), plus there is a dry period of 8-mo without frost. The reference evapotranspiration is $1272 \mathrm{~mm}$ per year, with January being the peak month with $190 \mathrm{~mm}$. Relative humidity is homogeneous in summer, between $55-65 \%$, and in winter ranges from 60 to $85 \%$. 
The soil of the experimental plot is a sandy clay loam of the Pocuro Series family member fine silty, mixed, thermal of fluventic haploxerolls (Mollisol) (CIREN, 1997), with a field capacity of $323 \mathrm{~mm}$ for the first $60 \mathrm{~cm}$ of soil.

\section{Irrigation treatments}

We applied two irrigation treatments, each in an area of $404.5 \mathrm{~m}^{2}$ which contained 33 plants; the eight central plants were used for measurements and analyses. Drip irrigation was used, with emitters separated by $1 \mathrm{~m}$ and a flow of $4 \mathrm{~L} \mathrm{~h}^{-1}$, which gave a precipitation of $1.15 \mathrm{~mm} \mathrm{~h}^{-1}$. The control irrigation treatment (CT) was applied during the entire season with amounts of water equivalent to $100 \%$ crop ETc, while in the "moderate deficit" treatment (DT) the irrigation was $50 \%$ ETc.

\section{ETc determination}

We calculated ETc as the product of the reference evapotranspiration (ETo), calculated with the method of Penman-Monteith (Doorenbos and Pruitt, 1977), and the crop coefficient (Kc) proposed by Williams et al. (2003). ETc was considered to be $90 \%$ of total irrigation water applied, due to the efficiency of the drip irrigation system.

We studied two periods of $23 \mathrm{~d}$ each during the 2004-2005 season. The first period was from 82 to $105 \mathrm{~d}$ after bud break (DABB) during the second stage of the annual TDV cycle (Figure 1a) and the second was from 112 to $135 \mathrm{DABB}$, during stages 3 and 4 of the TDV cycle, in which reproductive growth predominates. The CT plants were irrigated five times during each period. DT plants were watered three times in each period. All irrigation treatments provided same amount of water.

\section{Soil water content and water potencial}

We determined volumetric (\%) soil water content each 10 $\mathrm{cm}$ up to $60 \mathrm{~cm}$. Around each plant we installed six access tubes for Delta-T Profile probes type PR-1 (Delta-T, England; Sensor type Frequency Domain Reflectometry; FDR, Muñoz-Carpena, 2004). Two tubes were located in the row at 50 and $100 \mathrm{~cm}$ from the plant; the other four were placed between rows at $30,60,90$, and $120 \mathrm{~cm}$ from the plant. Measurements were made at 10, 20, 30, 40, and $60 \mathrm{~cm}$ depth in each access tube. Soil water content was expressed as the percentage of soil available water (SAW), where $100 \%$ is field capacity. We used the mean of 30 measurements (five for each of six access tubes) to estimate a value of SAW which represents the volume covered by the roots of the plant.

When the sun was near its zenith, between 13:00 and 14:30 h, we measured leaf ( $\left.\Psi_{\text {(leaf) }}\right)$ and stem water potentials $\left(\Psi_{(\text {stem) }}\right)$ (Choné et al., 2001; Williams and Araujo, 2002) using the pressure chamber method (Scholander et al., 1965), in leaves which were about 30 $\mathrm{cm}$ from the apex of a shoot, extended and exposed to the sun. In each period we made four measurements of $\Psi_{\text {(leaf) }}$ and nine of $\Psi_{(\text {stem) }}$ for each treatment.

\section{Variation in trunk diameter}

In three plants of each treatment, we installed electronic dendrometers (Model DE-1M, Phytech, Rehovot, Israel). The dendrometers were placed at $1.3 \mathrm{~m}$ above the ground; in the contact zone of the sensor and the trunk we removed bark, following the suggestion of van Leeuwen et al. (2000). Trunk diameter measurements were recorded every $30 \mathrm{~min}$ in a data acquisition center. The variables used were the maximum daily trunk contraction (MDS, $\mu \mathrm{m}$ ), minimum and maximum daily diameter growth (MNTD and MXTD), and total minimum and maximum accumulated growth from the beginning of the measurement period (Figure 1).

\section{Sensitivity analysis}

The sensitivity analysis of data was calculated as a function of the relative responses of $\Psi_{\text {(leaf) }}, \Psi_{\text {(stem) }}$, (DT/CT), and TDV(CT/DT), following Goldhamer et al. (1999) and Moriana and Fereres (2002). We regressed DT response on CT values, considering the value of slope as an indicator of the sensitivity and degree of fit to a straight line as an indicator of the linearity of the response between DT and CT as proposed by Goldhamer et al. (1999), except that we obliged the line to pass through the origin to avoid the constant of the linear function which may complicate the analysis. Finally, to examine the variability of the responses we calculated the signal:noise ratio, defined as the relation between the percentage difference of DT with respect to CT and the coefficient of variation of the measurements (Goldhamer and Fereres, 2001; Intrigliolo and Castel, 2007).

\section{RESULTS}

\section{First period, 82-105 DABB}

Soil water content and water potential. Soil available water (SAW) had initial values of $105 \%$ and $92 \%$ in CT and DT, respectively (Figure 2a). The mean SAW during the period was $100.4 \pm 2.36 \%$ SAW in CT and $84.5 \pm$ $4.61 \%$ SAW in DT. The minimum water content in CT plants was $97.3 \%$ SAW (98 DABB), while for DT it was $79.6 \%$ SAW (104 DDB).

CT had $\Psi_{\text {(leaf) }}$ values ranging from -0.8 to $-1.01 \mathrm{MPa}$, while DT extreme values were -0.75 to $-0.94 \mathrm{MPa}$. Values of $\Psi_{\text {(stem) }}$ ranged from -0.69 to $-0.89 \mathrm{MPa}$ in CT and -0.75 to $-0.94 \mathrm{MPa}$ in DT. The differences between CT and DT were significant $(\mathrm{p}<0.05)$ at days 98 and 104 DABB for $\Psi_{\text {(leaf) }}$ and for days 82, 84, 102, and 104 for $\Psi_{\text {(stem) }}$ (Figure $2 b)$. For every $10 \%$ decrease in SAW, $\Psi_{\text {(leaf) }}$ decreased on average by $0.046 \mathrm{MPa}$ and $\Psi_{\text {(stem) }}$ by $0.058 \mathrm{MPa}$; thus the latter measure was more sensitive to a decrease in soil water. 


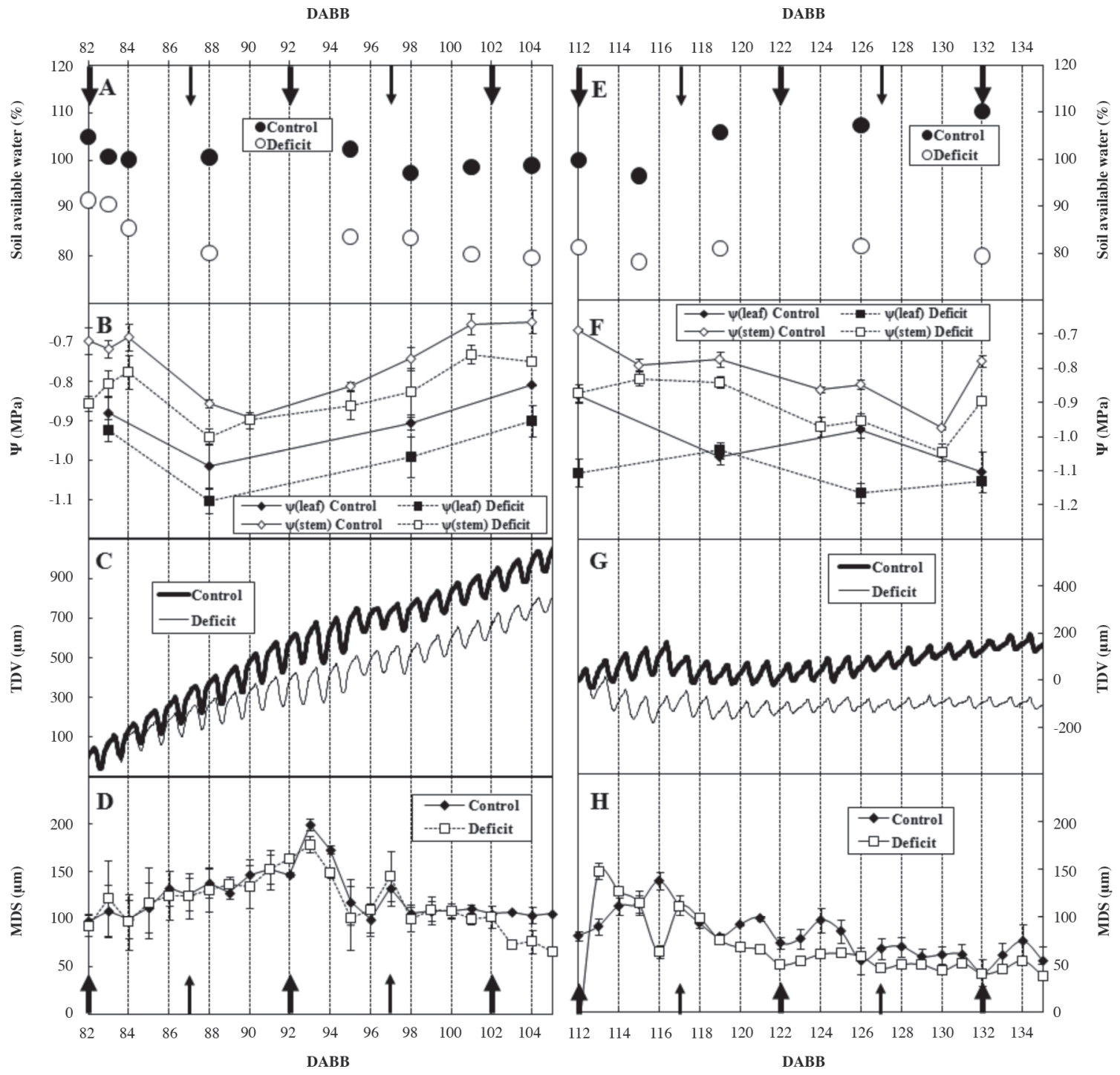

Figure 2. (A) Soil available water (SAW); (B) Leaf water potential ( $\left.\Psi_{(\text {leaf })}\right)$ and stem water potential ( $\left.\Psi_{(\text {stem) }}\right)$; $(C)$ trunk diameter variation (TDV); and (D) maximum daily trunk shrinkage (MDS) from 82 to $105 \mathrm{~d}$ after bud break (DABB). Vertical arrows indicate irrigation times in both treatments (thick arrows) or only in the control (thin arrows). (E) SAW; (F) $\Psi_{\text {(leaf) }}$ and stem $\Psi_{(\text {stem) }}$; (G) TDV; and (H) MDS from 112 to 135 DABB.

Variation in trunk diameter. At the end of the first period MXTD reached $1080.8 \mu \mathrm{m}$ in CT and $845.9 \mu \mathrm{m}$ in DT, while MNTD reached 975.3 and $779.8 \mu \mathrm{m}$ in CT and DT, respectively (Figure 2c). Thus the water deficit reduced trunk growth by $21 \%$. MDS was similar in both treatments during the entire period, with values ranging from 66 to $200 \mu \mathrm{m}$ (Figure 2d); MDS values were slightly higher for CT. In both treatments MDS increased until $95 \mathrm{DABB}$, after which it decreased to about $100 \mu \mathrm{m}$. MXTGR ranged from 69 to $-3.85 \mu \mathrm{m}$ $\mathrm{d}^{-1}$ for CT (mean $45.3 \mu \mathrm{m} \mathrm{d}^{-1}$ ), while for DT it ranged from 60 to $12.5 \mu \mathrm{m} \mathrm{d}^{-1}$ with a mean of $35.2 \mu \mathrm{m} \mathrm{d}^{-1}$. The MNTGR of CT varied from 106.1 to $-53 \mu \mathrm{m} \mathrm{d}^{-1}$ with a mean of $41.33 \mu \mathrm{m} \mathrm{d}^{-1}$, while the corresponding values for DT were 91 to $-57.5 \mu \mathrm{m} \mathrm{d}^{-1}$ with a mean of $32.5 \mu \mathrm{m} \mathrm{d}^{-1}$.

\section{Second period 112-135 DABB}

Soil water content and water potential. At the beginning of this period SAW was $99.7 \%$ and $81.3 \%$ in CT and DT, respectively (Figure 2e). The mean SAW in the period was $103.8 \pm 5.6 \%$ for $\mathrm{CT}$ and $80.3 \pm 1.5 \%$ for DT, with minima of $96.4 \%$ (115 DABB) in CT and in $78.2 \%$ (115 DABB) in DT.

In this period $\Psi_{\text {(leaf) }}$ varied between -0.88 and $-1.1 \mathrm{MPa}$ in $\mathrm{CT}$ and between -1.04 and $-1.13 \mathrm{MPa}$ in DT (Figure 2f). Values of $\Psi_{\text {(stem) }}$ ranged from -0.68 to $-0.97 \mathrm{MPa}$ in $\mathrm{CT}$, while for DT the range was from -0.83 to $-1.04 \mathrm{MPa}$. There were significant differences $(\mathrm{p}<0.05)$ at 112 and $126 \mathrm{DABB}$ for $\Psi_{\text {(leaf) }}$, and at 112, 119, 124, 126 and 132 DABB for $\Psi_{\text {(stem) }}$. In this period, for every $10 \%$ that SAW decreased, $\Psi_{\text {(leaf) }}$ decreased by $0.042 \mathrm{MPa}$ and $\Psi_{\text {(stem) }}$ decreased by $0.045 \mathrm{MPa}$. 
Variation in trunk diameter. At the end of the second experimental period, MXTD reached $188.3 \mu \mathrm{m}$ in CT and $-83.9 \mu \mathrm{m}$ in DT, with a MNTD of $135.38 \mu \mathrm{m}$ in CT and $-120.8 \mu \mathrm{m}$ in DT (Figure 2g). Values of MDS were small in the first period, on 12 of the days they were greater in CT than in DT (Figure 2H). The values for MXTGR were between -19 and $26 \mu \mathrm{m} \mathrm{d}^{-1}$ in CT and between -21.5 and $10 \mu \mathrm{m} \mathrm{d}^{-1}$ in DT, while MNTGR ranged from -23 to 39 $\mu \mathrm{m} \mathrm{d}^{-1}$ in CT and from -52 to $10.4 \mu \mathrm{m} \mathrm{d}^{-1}$ in DT.

\section{Relative response of DT}

During the first period the sensitivity was greater in SAW than in $\Psi$ (Figure 3a). However, the most constant relative responses, that is those which were sensitive during the entire first measuring period, were those of the accumulated growth (MXTD, MNTD). The relative response of MDS was close to 1 during the whole period (Figure 3c). In the second period, the relative responses of $\Psi_{\text {(leaf) }}$ and $\Psi_{\text {(stem) }}$ were similar, and as in the first period, lower than the relative response values of SAW (Figure 3b). The relative responses of MNTGR and MXTGR were considerably less than in the first period, and also had negative values. For this reason, we added the absolute value of the minimum recorded measurement $(181 \mu \mathrm{m})$ to MNTD and MXTD of both treatments to simplify the analysis. Thus, we obtained positive values for the relative responses of MNTD and MXTD, which were greater in the second period (Figure 3d). In both periods the relative responses of MDS were close to one. In the linear regression of CT on DT, the slope indicates the sensitivity of the indicator, and the fit $\left(\mathrm{R}^{2}\right)$ indicates the linearity of the response. In the first period $\Psi_{\text {(stem) }}$ had a greater slope than $\Psi_{\text {(leaf) }}$ (Figure 4a) with similar levels of fit, which indicates a greater amplitude of the mean response of $\Psi_{\text {(stem) }}$ during the period. The indicators of accumulated growth (MNTD, MXTD) had greater slopes and better fits (Figure 4c), while those of growth rate (MXTGR, MNTGR) had poorer fits, showing less linearity of these responses to the irrigation treatments (Figure 4e). This was probably due to the fact that growth rates depend on the size of the plants, and to the sensitivity of the measurement system.

The equivalent analyses for the values obtained in the second period found coefficients of determination which were considerably lower for the responses of both indicators of $\Psi$ (Figure $4 \mathrm{~b}$ ) than in the first period.A similar result was found in the indicators of accumulated growth (MNTD and MXTD), although the fit was somewhat better for MNTD (Figure 4d). Since the growth rates were lower, the responses of both treatments produced points close to the origin and did not have a good fit for MXTGR or MNTGR (Figure 4f).

The signal:noise ratio in the first period had values between 1.4 and 1.49 for $\Psi_{\text {(stem) }}$, MXTD and MNTD and 1.33 for MXTGR; the value for $\Psi_{\text {(leaf) }}$ was one. In the second period the signal:noise ratio for MNTD was 10.17, which means that the difference between treatments was more than 10 times the variability, followed by a value of 8 for MXTD. The ratio for $\Psi_{\text {(stem) }}$ was 2.43 , greater than in the first period, while $\Psi_{\text {(leaf) }}$ had a similar signal:noise ratio (Table 1).
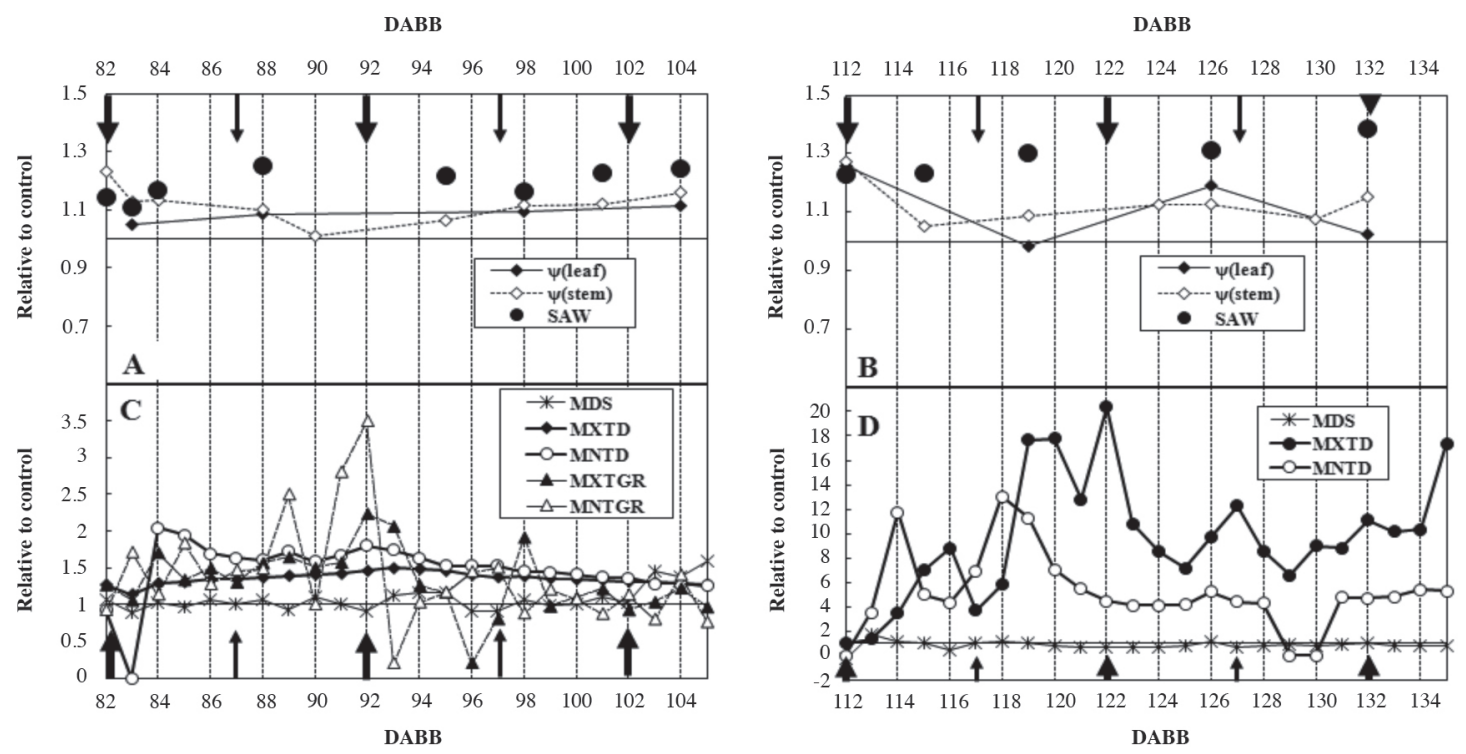

DABB: days after bud break; MDS: maximum daily trunk shrinkage; MXTD: maximum daily trunk diameter; MNTD: minimum daily trunk diameter; MXTGR: maximum trunk growth rate; MNTGR: minimum daily trunk growth rate.

Vertical arrows indicate irrigation times in both treatments (thick arrows) or only in the control (thin arrows).

Figure 3. Relative responses of deficit compared to control treatment in soil water content (SAW, Control/Deficit), leaf ( $\Psi_{(\text {leaf })}$ and stem water potential $\left(\Psi_{(\text {stem })}\right)$ (Deficit/Control) for the first (A) and second experimental periods (B). Relative response (Control/Deficit) of the indicators of trunk diameter variation for the first $(C)$ and second periods (D). 

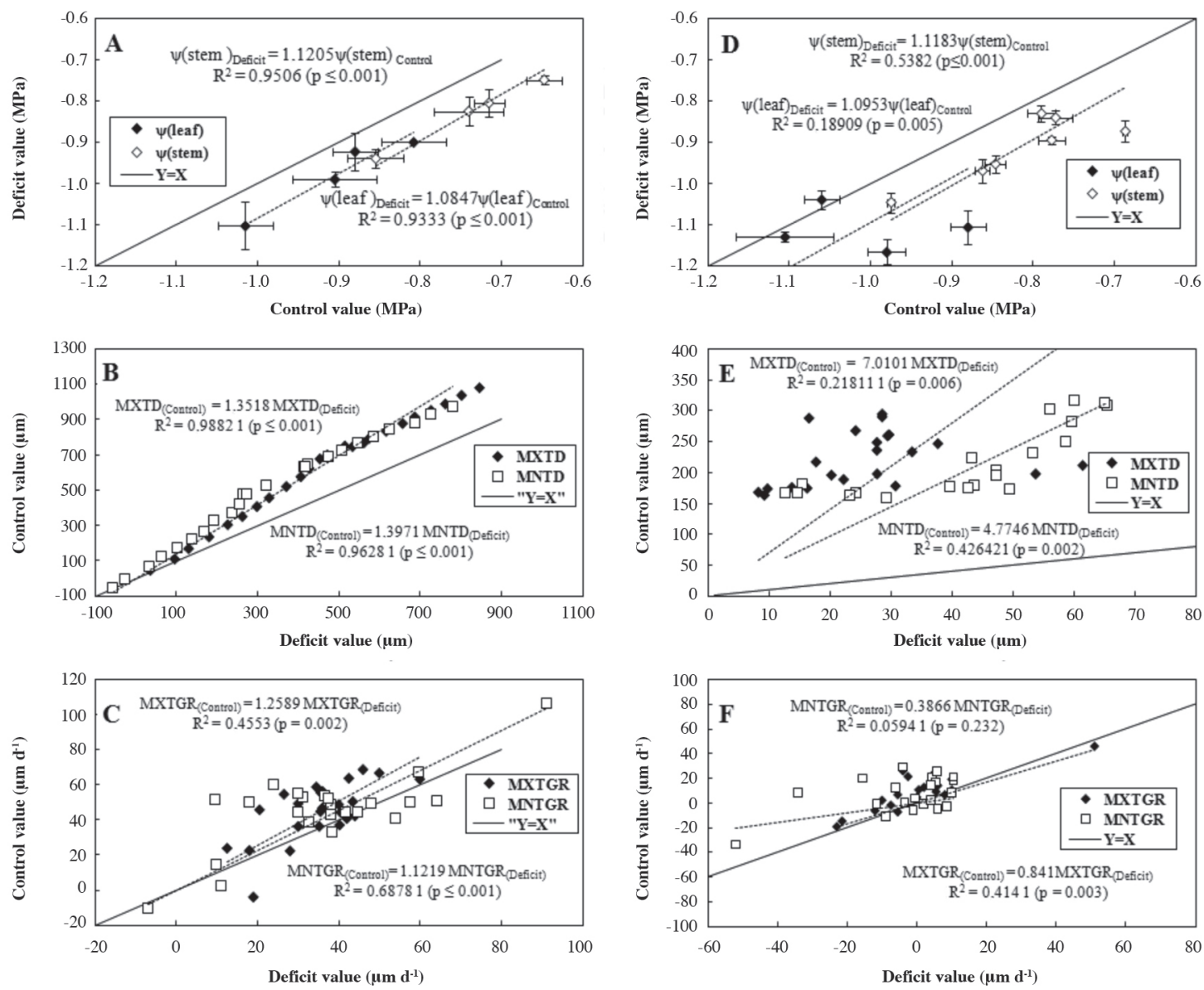

Figure 4. Linear regressions, passing through the origin, of the indicators of plant water status. $\Psi_{\text {(leaf) }}$ and $\Psi_{\text {(stem) }}$ in the first (A) and second (B) periods. Linear regressions of the responses of control and deficit treatment for minimum daily trunk diameter (MXTD) and minimum daily trunk diameter (MNTD) in the first (C) and second (D) periods. Linear regressions of the responses of Control and Deficit for maximum daily trunk growth rate (MXTGR) and minimum daily trunk growth rate (MNTGR) in the first (E) and second (F) periods.

Table 1. Signal (percent difference between responses of deficit treatment and control):noise (coefficient of variation) ratio of the variables evaluated in the two measurement periods.

\begin{tabular}{|c|c|c|c|c|c|c|c|c|}
\hline & SAW & MDS & MXTD & MXTGR & MNTD & MNTGR & $\Psi$ (leaf) & $\Psi($ stem $)$ \\
\hline \multicolumn{9}{|l|}{ 82-105 DABB } \\
\hline Signal, \% & 19.04 & -5.25 & 36.11 & 35.33 & 38.43 & 35.28 & 7.84 & 10.20 \\
\hline Noise (cv.), \% & 27.84 & 14.75 & 25.37 & 28.99 & 25.84 & 26.91 & 7.86 & 6.90 \\
\hline Signal/noise & 0.60 & -0.36 & 1.42 & 1.22 & 1.49 & 1.31 & 1.00 & 1.48 \\
\hline \multicolumn{9}{|l|}{$112-135$ DABB } \\
\hline Signal, $\%$ & 29.26 & -8.40 & 198.98 & - & 259.90 & - & 11.29 & 12.65 \\
\hline Noise (cv.), \% & 29.69 & 11.60 & 24.86 & - & 25.55 & - & 10.61 & 5.20 \\
\hline Signal/noise & 0.99 & -0.72 & 8.00 & - & 10.17 & - & 1.06 & 2.43 \\
\hline
\end{tabular}

SAW: Available soil water; MDS: maximum daily trunk shrinkage; MXTD: maximum daily trunk diameter; MXTGR: maximum daily trunk growth rate; MNTD: minimum daily trunk diameter; MNTGR: minimum daily trunk growth rate; $\Psi$ (leaf): leaf water potential; $\Psi$ (stem): xylem water potential; DABB: days after bud break.

\section{DISCUSSION}

Response of the indicators to the irrigation treatments Although the water content for DT was less than that of $\mathrm{CT}$ in both measurement periods and remained relatively high, the lowest SAW was equivalent to $32 \%$ of the volume, which is explained by the high water retention capacity of the soil due to its high porosity ( $52 \%$ of the volume), which is almost completely due to micropores (Silva, 2006).

Both treatments had values of $\Psi_{\text {(leaf) }}$ greater than -1 MPa, which has also been reported for plants of 'Thompson Seedless' (Araujo et al., 1995; Williams and Baeza, 2007), and 'Chardonnay' (Williams and Araujo, 
2002) irrigated with $100 \%$ ETc, and greater than plants of 'Thompson Seedless' (Araujo et al., 1995; Williams et al., 2010) and 'Barlinka' (Myburg, 1996) irrigated with deficit. Although SAW values were similar in both periods, $\Psi_{\text {(leaf) }}$ values were lower in both treatments, due to the greater deficit of vapor pressure (up to $5.0 \mathrm{kPa}$, Silva-Contreras et al., 2008). However, these values were greater than those reported in plants of 'Sauvignon Blanc' and 'Cabernet Sauvignon' (Williams and Araujo, 2002) irrigated with water deficit (from -1 to $-1.2 \mathrm{MPa}$ ). The $\Psi_{\text {(leaf) }}$ of DT showed a considerable response (about $7 \%$ lower with respect to CT), even though the water deficit utilized was moderate and did not originate SAW values less than $80 \%$.

In the case of $\Psi_{\text {(Stem) }}$, CT stayed above -0.9 MPa in both periods, consistent with the results reported by Myburg (1996) and Sellés et al. (2004) for grapevines irrigated with $90 \%$ and $100 \%$ of the calculated water demand, respectively. DT had a similar behavior in the first period, with values close to those of 'Cabernet Sauvignon' plants with a similar irrigation regime (Williams and Araujo, 2002). There were significant differences between treatments $(\mathrm{p}<0.05)$. Both $\Psi_{\text {(leaf) }}$ and $\Psi_{\text {(Stem) }}$ showed responses to irrigation treatments, showing that they affected the $\Psi$ variables.

The lower values found during the first period in the MXTGR and MNGTR DT with respect to the control coincide with the results of Myburg (1996), Sellés et al. (2004), and Intrigliolo and Castel (2007), given that vegetative growth is the process most sensitive to lack of water. The difference between treatments was accumulative, both for MNTD and MXTD. The growth trend did not differ notably between treatments, perhaps due to the fact that the water deficit was not severe.

Intrigliolo and Castel (2007) rejected the use of TDV as in indicator of the water state of grapevines after veraison. During the second period of our study, values of MNTD and MXTD did not show the effect of radial growth of the trunk, and were even negative for a few days. During the veraison period, the demand for assimilates is dominated by grapes, while in the first phase it is not (Figure 1); thus in the fourth stage of annual development of the trunk, the fruit growth is predominant and there is also a redistribution of the water absorbed by the plant to supply the reproductive growth (Silva-Contreras et al., 2008). Thus in the post-veraison there was no growth of the trunk, given that cellular turgidity is the component which is dominant in trunk diameter variation, and thus in its growth. The trends observed in MNTD and MXTD (Figure 2e, 2f) were different between treatments when scaled with respect to an initial variation. This variation, due to the changes in water content of the tissues, has been proposed as indicator for irrigation control in grapevines which are continuously irrigated in the post-veraison (Kopyt and Ton, 2005).

MDS has been suggested as a good indicator of the water state of grapevines in soils with low water retaining capacity (Myburg, 1996; van Leeuwen et al., 2000). However, in our study the two treatments had similar values in both measurement periods; in fact, the $\mathrm{CT}$ value was greater in the majority of the measurements. This may be due to the edaphic conditions of our experimental site, with a high water retaining capacity and little aeration, which limits the capacity of the roots to absorb water (Richards, 1983). Myburg (1996) proposed an MDS threshold of $400 \mu \mathrm{m}$ for the diagnosis of water deficit; this value is much greater than our measurements, which were all less than $200 \mu \mathrm{m}$. In our study, MDS did not show sensitive responses to the irrigation treatments. This may be because high water availability increases the elasticity of the cell walls, and low soil aeration may have diminished the water absorption capacity of the roots in the control CT, making its MDS values similar to those of DT.

\section{Sensitivity of the indicators to the irrigation treatments and their use for irrigation scheduling}

Although the relative response to CT of SAW was greater than both measurements of $\Psi$ in every measurement, it had a coefficient of variation between measurements close to $30 \%(n=30)$. Fernández-Gálvez and Simmonds (2006) measured the redistribution of water in the soil for periods of $1 \mathrm{~d}$; thus it is necessary to measure several points in the evaluated soil space to obtain a representative measure. Since our measurements were made more frequently than applied irrigation, it is convenient to obtain measurements of SAW which include as much of soil volume as possible. The relative response of $\Psi_{\text {(leat) }}$ was similar to that of $\Psi_{\text {(stem) }}$ in both measurement periods. Naor (1998) and Choné et al. (2001) suggested that $\Psi_{\text {(stem) }}$ is more sensitive than $\Psi_{\text {(leaf) }}$ to the soil water content and is also less variable; while Araujo et al. (1995) and Williams et al. (2010) proposed that $\Psi_{\text {(leaf) }}$ is a sufficient indicator for the control of the water status in 'Thompson Seedless' vines. Shultz (2003) indicated that there are varietal differences for the control of leaf water state in grapes; some varieties have a greater stability of $\Psi_{\text {(leaf) }}$ when there is variation in water availability. For 'Crimson Seedless' we observed a proportional response for both measurements. The lower degree of linearity in the responses of the water potential in the second period may be related to physiological changes due to fruit development. However, in both periods we obtained responses sensitive to the irrigation treatments.

Regression analyses were performed to evaluate the linear relationships on the responses of CT and DT, from which proportional threshold values may be established for the reference plants which were irrigated at a greater rate than the rest of the orchard, as proposed by Goldhamer and Fereres (2001) and Moriana and Fereres (2002). The poorer linear fit on the responses of MNTGR and MXTGR makes not practical the establishment of thresholds proportional to plants "irrigated correctly" as Goldhamer 
and Fereres (2001) proposed. The greater slopes in the responses of MNTD and MXTD compared to the growth rates occurred because the former are cumulative; thus the response was more sensitive for both periods, especially in the second. Although there was not a good linear fit of the responses, the values were considerably greater than expected with a slope of one (Figure 4).

The variability of the indicators of TDV has been reported as too big; for this reason they were rejected as indicators for irrigation scheduling in apples (Naor and Cohen, 2003) and wine grapes (Intrigliolo and Castel, 2007). However, we found a similar signal:noise ratio between MNTD, MXTD, and $\Psi_{\text {(stem) }}$ in the first period, which is due to the strength of response of indicators of TDV, that is, to the strength of the signal. The variability of the indicators of TDV (Table 1) was less than that reported by Intrigliolo and Castel (2007). This may be explained by the lower water deficit in our experiments; Fuchs (1990) suggested that the variability of plant measures increases with greater water stress. In the second period the signal:noise ratios of MNTD and MXTD were greater than those of $\Psi$; however, all were greater than those of the first period, in agreement with the suggestions of Ton et al. (2004) and Kopyt and Ton (2005), who based their diagnosis of the water state of the plant on the increases and decreases in trunk diameter during the period of fruit maturation.

The signal:noise ratios of the indicators of TDV for each cycle of irrigation (Figure 5) were notorious in the last day of the first watering cycles of the first period (82$105 \mathrm{DABB})$, but were close to 1 in the remainder. In the second period (112-135 DABB) the relation was greater

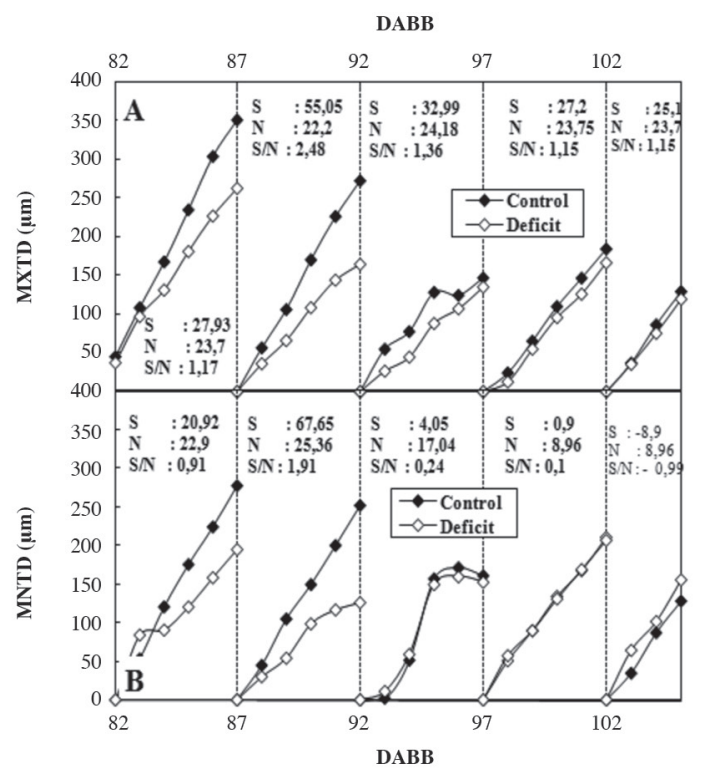

and $>1$ in the four irrigation cycles. The persistence of the response to TDV was low during the second development stage of the trunk (first measurement period), which is evident by the lack of different responses between CT and DT in the last two cycles. Williams et al. (2010) found greater levels of water productivity (production per unit of water used) for plants irrigated with less than the atmospheric water demand. This, along with our results, indicates internal mechanisms (changes in cell wall elasticity and/or osmotic adjustment) of the control of water state of the plant. These mechanisms may function to maintain the vegetative growth or cellular turgidity under conditions of moderate water deficit when the fruit is growing. This may make the use of indicators of TDV feasible in conditions of frequent irrigation, contrary to the conclusion of Jones (2004) but in agreement with the results of Ton et al. (2004) in fruit orchards.

We did not find a significant regression of TDV on $\Psi$, which may be due to the physical type of the variables. The indicators of TDV are extensive variables, and therefore depend on the quantity of material, in this case the size of the trunk, while $\Psi$ is an intensive variable, that is, independent of the size of the trunk and equivalent in any part of the trunk or its behavior (for example see Brown et al., 2004). To this must be added the sensitivity of the measuring instrument (LVDT system) which is about $\pm 5 \mu \mathrm{m}$, quite large considering the range of the measurements, and which could interfere with the establishment of clear tendencies for TDV. These limitations explain the large variability of TDV indicators between plants and the difficulty in establishing threshold values, since the absolute value of a TDV indicator may

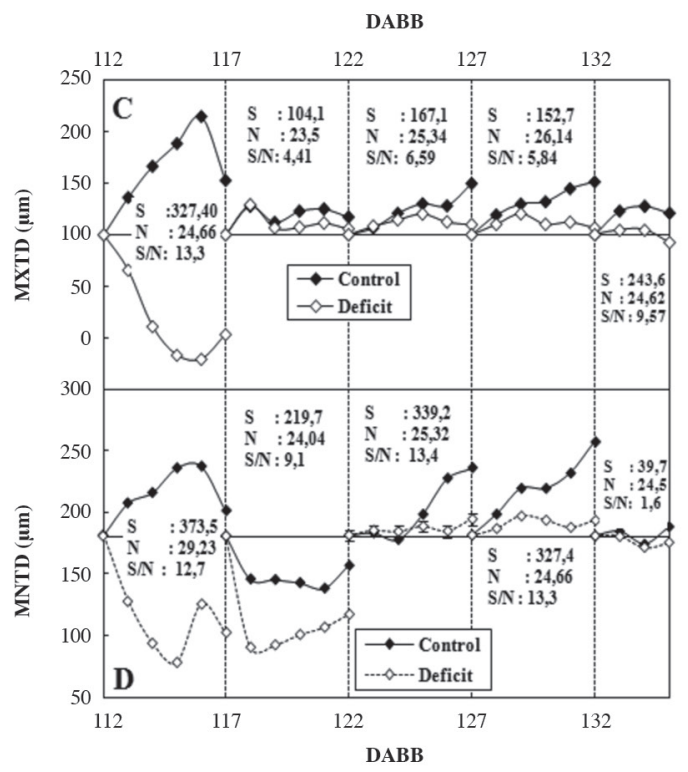

DABB: days after bud break;

Figure 5. Daily maximum (MXTD) and minimum (MNTD) trunk diameters for the two measurement periods in 5-d intervals corresponding to irrigation cycles. For the first period, MXTD (A) and MNTD (B) and for the second period, MXTD (C) and (D) MNTD. For each irrigation cycle, the signal:noise ratio for the final day is given. 
have a different interpretation from one plant to the next. This suggests the use of an intensive indicator of TDV, such as relative variation, studied with models (Génard $e t$ $a l ., 2001)$. Thus, it is possible to improve the management of the information of TDV indicators and to improve the diagnostic capacity of the water state of grapevines. Consistent with this idea is the fact that in the first period we found significant regressions of the relative values of MNTGR and MXTGR on the relative values of $\Psi_{\text {(stem) }}$ for $\mathrm{CT}$, and in the second period there were significant regressions of the responses of MNTD and MXTD on the relative responses of $\Psi_{\text {(stem) }}$, which reflect the relation between TDV and the water status of the plant (Figure 6). Thus for irrigation scheduling using TDV indicators it is useful to have one or more plants in the orchard with more irrigation than the rest, which may be obtained with a larger number of emitters, in order to compare their TVD tendencies with the rest of the plants of the orchard, or to compare plants among different irrigation sectors or with different regimes in the same environmental conditions. Similar recommendations were made by Goldhamer and Fereres (2001) and Moriana and Fereres (2002).

Our results suggest that in order to choose one or more of the studied plant indicators, economic-productivity factors such as the cost of equipment and infrastructure and labor costs to make the measurements are more important than technical factors or sensitivity. TDV has the advantage of being a continuous indicator, that is, it is recorded during the entire day, and the disadvantage of requiring expensive equipment which needs careful maintenance. By comparison, $\Psi$ has the advantage requiring a simple apparatus and easy measurement, but

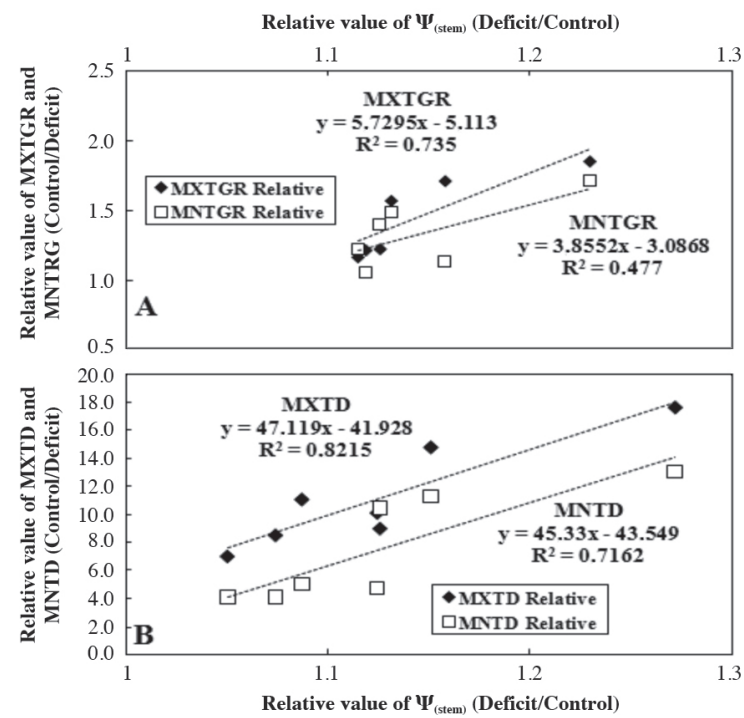

Figure 6. Linear regressions of the relative response (Deficit/Control) of the stem water potential $(\Psi($ stem $))$ on the relative response of minimum daily trunk growth rate (MNTGR) and maximum daily trunk growth rate (MXTGR) (Control/Deficit) during the first measurement period (A). Linear regressions of the relative response (Deficit/Control) of $\Psi($ stem) on the relative response of MNTGR and MXTGR (Control/Deficit) during the second measurement period $(B)$. the disadvantage of being a discrete measurement, that is, it represents only the moment of the day in which it is measured. This can improve with more measurements during irrigation cycle.

\section{CONCLUSION}

Our results show that dendrometry based on the expansion and contraction of organs allows the precocious and quantitative detection of the plant response to the real soil water availability in the periods of vegetative and reproductive growth. We found that, since TDV is a measurement of the plant size and can be measured with a high degree of sensitivity, even though it was more variable than the measurement of water potential, the response of plants with water deficit compared to control plants was greater. Since TDV generates extensive variables which are sensitive to water deficit, future studies to improve management of the information of dendrometric indicators are justified, in order to obtain intensive variables which reduce the variability and allow the establishment of threshold values. The continuity of dendrometric measurements, in contrast with the measurement of water potential, allows irrigation strategies to maximize plant growth to be defined in real time.

Variación del potencial hídrico y del diámetro del tronco como respuestas sensibles a la disponibilidad de agua en uva de mesa. La variación del diámetro del tronco (TDV) ha sido propuesta como un indicador del estado hídrico de las plantas, con resultados aparentemente contradictorios. En Vitis vinifera L. var. Crimson Seedless se evaluó la respuesta del potencial hídrico $(\Psi)$, indicador normalmente utilizado para definir el estado hídrico de las plantas y TDV, frente a dos tratamientos de riego, 100\% y 50\% de reposición de la evapotranspiración del cultivo (ETc), para determinar si la TDV es más apropiada que el $\Psi$ para la evaluación del estrés hídrico en vides. Se consideraron dos períodos de evaluación consistentes en lapsos de 23 días cada uno, el primero durante la fase de crecimiento exponencial del tronco, y el segundo durante el período de pospinta, momento en que el tronco detiene su tasa de crecimiento. En ambos períodos la TDV registró coeficientes de variación mayores al 25\%, frente a valores entre 7 y $10 \%$ registrados en el $\Psi$. Sin embargo, durante el primer período de medición (82 a 105 d después de brotación), los registros del crecimiento del tronco del tratamiento con déficit fueron inferiores al control con más de $30 \%$, mientras que la misma diferencia fue de entre 6 y $12 \%$ en las mediciones de $\Psi$. Durante el segundo período de medición (112 a 155 d después de brotación), en el cual predomina el crecimiento frutal, el control registró mediciones de TDV más de 100\% mayores al tratamiento con déficit hídrico, mientras $\Psi$ registró diferencias de entre 10 y $13 \%$. Estos resultados 
demuestran la sensibilidad de las variables continuas de TDV, y su utilidad como criterio de control de riego, considerando las características del desarrollo anual de las plantas.

Palabras clave: potencial hídrico, sensor de desplazamiento de variable, sensibilidad, Vitis vinifera.

\section{LITERATURE CITED}

Araujo, F., L.E. Williams, and M.A. Matthews. 1995. A comparative study of young Thompson Seedless grapevines under drip and furrow irrigation. II. Growth, water use efficiency and nitrogen partitioning. Scientia Horticulturae 60:251-265.

Brown, T.L., H.E. Lemay., B.E. Bursten, and J.R. Burdge. 2004. Chemistry: The central science. $9^{\text {th }}$ ed. 1045 p. Prentice Hall, Sao Paulo, Brasil.

CIREN. 1997. Estudio agrológico de la V Región. Publicación 116. Tomo I. 86 p. Centro de Información de Recursos Naturales (CIREN), Santiago, Chile.

Cifre, J., J. Bota, J.M. Escalona, H. Medrano, and J. Flexas. 2005. Physiological tools for irrigation scheduling in grapevine (Vitis vinifera L.). An open gate to improve water-use efficiency? Agriculture, Ecosystems \& Environment 106:159-170.

Choné, X., C. van Leeuwen, D. Dubourdieu, and J.P. Gaudillère. 2001. Stem water potential is a sensitive indicator of grapevine water status. Annals of Botany 87:477-483.

Doorenbos, J., and W. Pruitt. 1977. Crop water requirements. Irrigation and Drainage Paper 24. FAO, Rome, Italy.

Fernández-Gálvez, J., and L.P. Simmonds. 2006. Monitoring and modelling the three-dimensional flow of water under drip irrigation. Agricultural Water Management 83:197-208.

Fuchs, M. 1990. Infrared measurement of canopy temperature and detection of plant water stress. Theoretical and Applied Climatology 42:253-261.

Génard, M., S. Fishman, G. Vercambre, J.G. Huguet, C. Bussi, J. Besset, and R. Habib. 2001. A biophysical analysis of stem and root diameter variation in woody plants. Plant Physiology 126:188-202.

Goldhamer, D.A., and E. Fereres. 2001. Irrigation scheduling protocols using continuously recorded trunk diameter measurements. Irrigation Science 20:115-125.

Goldhamer, D.A., E. Fereres, M. Mata, J. Girona, and M. Cohen. 1999. Sensitivity of continuous and discrete plant and soil water status monitoring in peach trees subjected to deficit irrigation. Journal of the American Society for Horticultural Science $124: 437-444$

Intrigliolo, D.S., and J.R. Castel. 2007. Evaluation of grapevine water status from trunk diameter variations. Irrigation Science $26: 49-59$

Jones, H. 2004. Irrigation scheduling: Advantages and pitfalls of plant-based methods. Journal of Experimental Botany 55:24272436 .

Kadir, S., S. Ennahli, J. Griffin, R. Ryer, and M. Shelton. 2007. Growth, yield, fruit composition of 24 wine and table grape cultivars and selections. International Journal of Fruit Science 7:17-30.

Kopyt, M., and Y. Ton. 2005. Grapevine trunk expansion and microvariations: application to irrigation management. Australian \& New Zealand Grapegrower \& Winemaker 497(extra):27-35.

Matthews, M.A., and K.A. Shackel. 2005. Growth and water transport in fleshy fruit. In Holbrook, N.M., and M. Zwieniecki (eds.) Vascular transport in plants. p. 181-197. Elsevier Academic Press, Oxford, UK.

Moriana, A., and E. Fereres. 2002. Plant indicators for scheduling irrigation in olive trees. Irrigation Science 21:83-90.
Muñoz-Carpena, R. 2004. Field devices for monitoring soil water content. IFAS Extension Bulletin 343. 16 p. University of Florida Florida, USA.

Myburg, P.A. 1996. Response of Vitis vinifera L. cv. Barlika/ Ramsey to soil water depletion levels with particular reference to trunk growth parameters. South Africa Journal of Enology and Viticulture 17:3-14.

Naor, A. 1998. Relations between leaf and stem water potential and stomatal conductance in three field-grown woody species. Journal of Horticultural Science Biotechnology 73:431-436.

Naor, A. 2000. Midday stem water potential as a plant water stress indicator for irrigation scheduling in fruit trees. Acta Horticulturae 537:447-554

Naor, A., and S. Cohen. 2003. Sensitivity and variability of maximum trunk shrinkage, midday stem water potential, and transpiration rate in response to withholding Irrigation from field-grown apple trees. HortScience 38:547-551.

Nortes, P.A., A. Pérez-Pastor, G. Egea, W. Conejero, and R. Domingo. 2005. Comparison of changes in stem diameter and water potential values for detecting stress in young almond trees. Agricultural Water Management 77:296-307.

Reynolds, A., and A. Naylor. 1994. 'Pinot noir' and 'Riesling' grapevines respond to water stress duration and soil water-holding capacity. HortScience 29:1505-1510.

Richards, D. 1983. The grape root system. Horticultural Review 5:127-168.

Scholander, P.F., E.D. Bradstreet, E.A. Hemmingsen, and H.T Hammel. 1965. Sap pressure in vascular plants. Negative hydrostatic pressure can be measured in plants. Science 148:339-346.

Schultz, H.R. 2003. Differences in hydraulic architecture account for near-isohydric and anisohydric behaviour of two field-grown Vitis vinifera $\mathrm{L}$. cultivars during drought. Plant Cell and Environment 26:1393-1405.

Sellés, G., R. Ferreyra, I. Muñoz, and H. Silva. 2004. Physiological indicators of plant water status as criteria for irrigation scheduling in table grapes cv. Crimson Seedless, irrigated by drip. Acta Horticulturae 664:599-605.

Silva, C. 2006. Respuestas fisiológicas como indicadores para el control del riego en uva de mesa variedad Crimson Seedless. 42 p. Tesis de Ingeniero Agrónomo. Universidad de Chile, Facultad de Ciencias Agronómicas, Santiago, Chile.

Silva-Contreras, C., H. Silva-Robledo, G. Sellés-Von Schouwen, y R. Ferreyra-Espada. 2008. Relaciones de crecimiento entre el tronco y la baya en Vitis vinifera con uso de sensores de desplazamiento variable. Agrociencia 42:903-912.

Simonneau, T., R. Habib, J.P. Goutouly, and J.G. Huguet. 1993. Diurnal changes in stem diameter depend upon variations in water content: Direct evidence in peach trees. Journal of Experimental Botany 44:615-621.

Steppe, K., D.J. de Pauw, R. Lemeur, and P.A. Vanrollegem. 2006. A mathematical model linking tree sap flow dynamics to daily stem diameter fluctuations and radial stem growth. Tree Physiology $26: 257-273$

Steudle, E. 2004. The cohesion-tension mechanism and the acquisition of water by plant roots. Annual Review of Plant Physiology and Plant Molecular Biology 52:847-875.

Ton, Y., I. Kopyt, and N. Nilov. 2004. Phytomonitoring technique for tunning irrigation of vineyards. Acta Horticulturae 646:133-139.

van Leeuwen, C., O. Lerich, O. Renard, O. Tregoat, and P. Alla 2000. Micromorphometric changes in trunk diameter in relation to mild water stress in field grown vines. Journal International des Sciences de la Vigne et du Vin 34:41-47.

Valenzuela, J., y A. Lobato. 2000. Reguladores de crecimiento: Giberelinas. p. 179-193. In Valenzuela, J. (ed.) Uva de mesa en Chile. Colección Libros INIA $N^{\circ} 5$. Instituto de Investigaciones Agropecuarias INIA, Santiago, Chile.

Williams, L.E., and F. Araujo. 2002. Correlations among predawn leaf, midday leaf, and midday stem water potential and their correlations with other measures of soil and plant water status. Journal of American Society of Horticultural Sciences 127:448-454. 
Williams, L.E., and J.E. Ayars. 2005. Grapevine water use and the crop coefficient are linear functions of the shaded area measured beneath the canopy. Agricultural and Forest Meteorology 132:201-211.

Williams, L.E., and P. Baeza. 2007. Relationships among ambient temperature and vapor pressure deficit and leaf and stem water potentials of fully irrigated, field-grown grapevines. American Journal of Enology and Viticulture 58:73-181.
Williams, L.E., D.W. Grimes, and C.J. Phene. 2010. The effects of applied water at various fractions of measured evapotranspiration on water relations and vegetative growth of Thompson Seedless grapevines. Irrigation Science 28:221-232.

Williams, L.E., C.J. Phene, D.W. Grimes, and T.J. Trout. 2003. Water use of mature Thompson Seedless in California. Irrigation Science 22:11-18. 